\title{
Kernos
}

Revue internationale et pluridisciplinaire de religion grecque antique

$11 \mid 1998$

Varia

\section{Introduction thématique au colloque}

\section{André Motte}

Édition électronique
URL : http://journals.openedition.org/kernos/1213

DOI : $10.4000 /$ kernos. 1213

ISSN : 2034-7871

Éditeur

Centre international d'étude de la religion grecque antique

Édition imprimée

Date de publication : 1 janvier 1998

ISSN : 0776-3824

\section{Référence électronique}

André Motte, «Introduction thématique au colloque », Kernos [En ligne], 11 | 1998, mis en ligne le 21 avril 2011, consulté le 20 avril 2019. URL : http://journals.openedition.org/kernos/1213 ; DOI : $10.4000 /$ kernos. 1213 


\section{Introduction thématique au colloque ${ }^{1}$}

Peut-être n'était-il pas inutile, en prenant pour base les résumés des communications qui nous étaient alors parvenus, de tenter de baliser quelque peu la route de la réflexion commune qui s'offrait à nous. Le thème proposé était assez nettement circonscrit, mais les sujets suggérés n'en étaient pas moins très diversifiés, comme l'étaient aussi les voies d'approche choisies. Pour nous guider à l'intérieur de ces labyrinthes complexes que forment les panthéons des cités grecques et, si possible, pour nous en extraire aussi quand viendrait le moment de les considérer dans leur ensemble avec un peu de recul, il nous fallait garder en réserve quelques fils conducteurs solides. Il s'agissait alors de prendre quelques points de repère, même s'ils n'étaient pas les seuls.

Une première série de questions relève d'une voie d'approche qui, pour être la plus traditionnelle, n'en demeure pas moins inévitable. C'est l'approche génétique et historique, celle que suggérait d'ailleurs, mais sans nulle exclusive, le sous-titre choisi : "Origines et développements ". Comment et sous quelles formes sont nés les premiers panthéons, solidaires de la naissance des cités, et où ont-ils puisé leurs racines? La question peut être posée dans toute sa généralité, et c'est le regretté $B$. Dietrich qui a abordé ce sujet redoutable. Mais beaucoup ont aussi soulevé ce genre d'interrogation à propos de telle ou telle cité donnée, ou tel ensemble de panthéons régionaux, comme ceux d'Asie mineure qui semblent avoir hérité de panthéons anatoliens beaucoup plus anciens. Une objection dérangeante, mais salutaire, fut faite par François de Polignac, à propos de la manière habituelle dont on formule cette problématique. Nous parlons de panthéons et de cités comme d'ensembles constitués et dont les éléments sont étroitement imbriqués, mais sommes sûrs que de telles catégories soient bien adéquates pour l'époque archaïque?

L'étude du devenir des panthéons dans l'histoire des cités n'est pas moins ardue lorsqu'on s'interroge sur les facteurs qui ont été les plus déterminants pour assurer leur maintien ou forcer leur évolution. Il nous paraît qu'ils forment, à un moment donné, des ensembles solidement structurés et dotés d'une forte capacité de résistance, mais susceptibles en même temps d'adap-

1 En l'absence du président E. Moutsopoulos, retenu par d'autres obligations, A. Motte, vice-président, a accueilli les participants au nom du C.I.E.R.G.A. et de l'Université de Liège. 
tations progressives, voire quelquefois de mutations profondes. Nous pressentons qu'ils n'évoluent pas au hasard, mais en fonction de données internes et externes, tributaires qu'ils sont des situations et des volontés politiques, des transformations culturelles et des changements de mentalités, des influences étrangères aussi, d'où une part de contingence n'est pas absente.

Souvent concurrente de cette approche, moins empirique peut-être et se voulant en tout cas plus radicale apparaît la méthode structurale. Elle aussi était suggérée, non dans le titre ou le sous-titre du colloque, mais bien dans la présentation du thème accompagnant l'invitation. On y rappelait, en effet, que l'apport des travaux de G. Dumézil pour le domaine indo-européen et les analyses de J.-P. Vernant pour la Grèce avaient ouvert la voie à une étude des panthéons envisagés comme des systèmes différentiels et classificatoires où la place et le rôle d'un dieu ne s'éclairent qu'au regard de l'ensemble dans lequel il s'insère. Un article de Marcel Detienne paru dans le dernier numéro de Kernos, le volume du $10^{\mathrm{e}}$ anniversaire, constitue une intéressante illustration du thème puisqu'il s'intitule : Expérimenter dans le champ des polythéismes. M. Detienne commence par rappeler les principes dont s'est inspiré Dumézil et à montrer comment a évolué sa méthode dans un sens toujours plus affiné. Plus Levi-straussien que jamais, il indique ensuite les avancées qu'il souhaite dans l'étude du polythéisme grec, en prenant notamment à témoin ses récentes recherches sur Apollon. Dans l'approche expérimentale qu'il préconise, - une véritable «manipulation " pour reprendre ses propres termes -, il s'agit de s'appliquer, par exemple, à faire réagir un dieu ou un groupe de dieux en présence de tel objet de la vie sociale ou du monde naturel, en évitant de se laisser séduire par la forme immédiate des figures divines, mais en cherchant, tel un micro-analyste, « les petits systèmes de pensées logés dans les assemblages des dieux ». Il faut donc se tenir'au plus près des données factuelles du champ polythéiste, passer par les détails concrets, objets, gestes et segments de situation. Explorer les microréseaux, tel est donc le mot d'ordre, si l'on peut dire, " chaque dieu étant d'abord au pluriel ». C'est sur cette expression forte que l'article se termine.

Je ne sais s'il est beaucoup d'intervenants au colloque qu'aurait tentés une telle démarche. Du moins faut-il reconnaître que l'approche structurale a déjà montré sa fécondité en bien des domaines. Dans l'exploitation des données archéologiques, par exemple, des recherches inspirées de cette méthode ont permis de montrer combien la structuration du paysage religieux qui s'opère en fonction des divinités protectrices d'une communauté avait été fondamentale dans la naissance et l'évolution de cette forme politique originale qu'a été la cité grecque.

Toute préoccupée de repérer les groupements, les agencements organisés, les rapports d'opposition et de complémentarité, l'approche structurale ne prétend pas pour autant, on vient de le voir, sonner le glas des monographies consacrées à une divinité particulière, à la condition bien sûr de travailler sur des microréseaux. Elle laisse cependant intacte à mes yeux la question 
de sa savoir si une divinité ne peut conserver, par delà les relations qui, dans un contexte donné, la constituent, une certaine identité.

Je voudrais encore évoquer, pour terminer, une problématique que plusieurs intervenants ont abordée par divers biais et qui manifeste une autre tension, liée cette fois à la diversité des sources mêmes que nous sommes appelés à exploiter. On sait, en effet, que les panthéons hiérarchisés des cités sont loin de coïncider toujours avec les panthéons qu'édifie la théologie de poètes comme Homère, Hésiode ou les Tragiques. Or, et ceci est plus inattendu peut-être, Annie-France Laurens nous a montré que certaines configurations panthéoniques qu'on rencontre sur des représentations figurées témoignaient de discordances semblables. Prenons aussi, avec Vinciane Pirenne-Delforge, l'exemple de Pausanias; il parcourt les cités, il consacre le plus grand soin à parler de leurs dieux, de leurs cultes et de leurs sanctuaires, mais, dans le même temps, sa théologie reste encore toute imbibée d'une vision homérique. En revanche, Neta Aloni-Ronen nous a fait voir des correspondances, parfois bien éclairantes, entre les données de la mythologie poétique et celles de la religion des cités. Comment démêler cet écheveau ?

Ce ne sont donc pas les questions qui nous ont manqué, et je n'en ai évoqué que quelques-unes. De quoi mettre le lecteur en appétit pour un « festin de paroles », comme dit Platon!

Comme annoncé dans l'éditorial, il n'a pas été possible de rassembler toutes les contributions dans ce volume de Kernos, compte tenu de leur nombre et de leur dimension. Une partie paraîtra dans un Supplément qui est sous presse et qui reprend 14 interventions ${ }^{2}$. La répartition s'est faite selon le critère thématique suivant. Dans ce numéro de Kernos sont reprises de préférence les communications qui concernent des divinités singulières ou un groupe particulier de divinités. Le Supplément accueille les contributions

2 N. Aloni-Ronen, Maryying Hera: Incomplete Integration in the Making of the Pantbeon; Fr. DE Polignac, Divinités régionales et divinités communautaires dans les cités archaïques; $\mathrm{Cl}$. AntonetTr, Le développement du pantbéon d'une métropole: Mégare; W. BURKERT, La cité d'Argos entre la tradition mycénienne, dorienne et bomérique; E. SUÁREz DE LA TORRE, Les dieux de Delphes et l'bistoire du sanctuaire (des origines au $I^{e}$ siècle avant J.-C.); P. Bonnechere, Les dieux du Trophonion lébadéen : pantbéon ou amalgame?; A. VERBANCK-PIÉrARD, Héros attiques au jour le jour: les calendriers des dèmes; V. Pirenne-Delforge, Le vocabulaire du divin et la notion de "pantbéon " chez Pausanias; Cl. CALAME, Logiques du temps légendaire et de l'espace cultuel selon Pausanias: une représentation discursive du "pantbéon de Trézène; M. PIÉRART, Omissions et malentendus dans la "Périégèse ": Danaos et ses filles à Argos; Y. LAFOND, Pausanias et le pantbéon de Patras: l'identité d'une cité grecque devenue colonie romaine; M. Osanna, Descrizione autoptica e rielaborazione "a tavolino " in Pausania: il caso di Aigeira; M. Jost, Versions locales et versions "panbelléniques" des mythes arcadiens chez Pausanias; C. Jourdain-ANnequin, Représenter les dieux: Pausanias et le pantbéon des cités. 
privilégiant une approche globale par cité ou par région, et regroupe notamment les articles traitant des problèmes que pose la lecture de la Périégèse de Pausanias à propos des panthéons locaux.

André MoTTe 